\section{Strength of the continental lithosphere: Time to abandon the jelly sandwich?}

\author{
James Jackson, University of Cambridge, Department of Earth Sciences, Bullard \\ Laboratories, Madingley Road, Cambridge CB3 OEZ, UK, jackson@esc.cam.ac.uk
}

\begin{abstract}
For the past two decades, many people (including me) have embraced the view that the continental lithosphere is like a jelly sandwich, with a weak lower crust lying between a strong upper crust and a strong uppermost mantle. A recent reassessment of earthquake depth distributions and gravity anomalies on the continents makes it difficult to maintain this view, suggesting instead that the seismogenic layer may be the only significant source of strength in the continental lithosphere, and that the upper mantle beneath the continents is relatively weak. This change of view, if it is correct, has several implications for continental geodynamics: (1) patterns of surface faulting on the scale of a few hundred kilometers are likely to be controlled by the anisotropic strength of
\end{abstract}

crustal blocks and their intervening faults; (2) flexure of the Indian shield is likely to be a major support of the topography in the Himalaya and southern Tibet; and (3) transient lowercrustal flow, of the type associated with metamorphic core complexes, is likely to be controlled by the input of igneous melts and fluid into the lower crust. Overall, this new view suggests that continental tectonics and mechanics are controlled by strength that resides mainly in the crust, rather than in the mantle.

\section{INTRODUCTION}

For almost 20 years, the prevailing view has been that the continental lithosphere generally consists of a weak lower crust sandwiched between a relatively strong upper crust and uppermost mantle (e.g., Chen and
Molnar, 1983). This view arose from studying the depth distribution of earthquakes, combined with an extrapolation of laboratory rock mechanics experiments to geological conditions (e.g., Brace and Kohlstedt, 1980). An important corollary is the conclusion that the largest contribution to the integrated vertical strength of the lithosphere comes from the upper mantle (e.g., Sonder and England, 1986; Molnar, 1992). This conclusion, in turn, has greatly influenced numerical models of continental deformation and implicitly supports the view that the behavior of the continental lithosphere as a whole is controlled by the strength of its creeping mantle component. I now believe that this popular "jelly sandwich" conception of the continental lithosphere and its corollary that the mantle is the strongest part of the lithosphere are both generally incorrect. Indeed, I now suspect that the opposite point of view, in which the behavior of the continental lithosphere is dominated by the strength of its upper seismogenic layer, is more likely to be correct. This article summarizes the reasons for this change in interpretation and outlines some of its implications for continental tectonics.

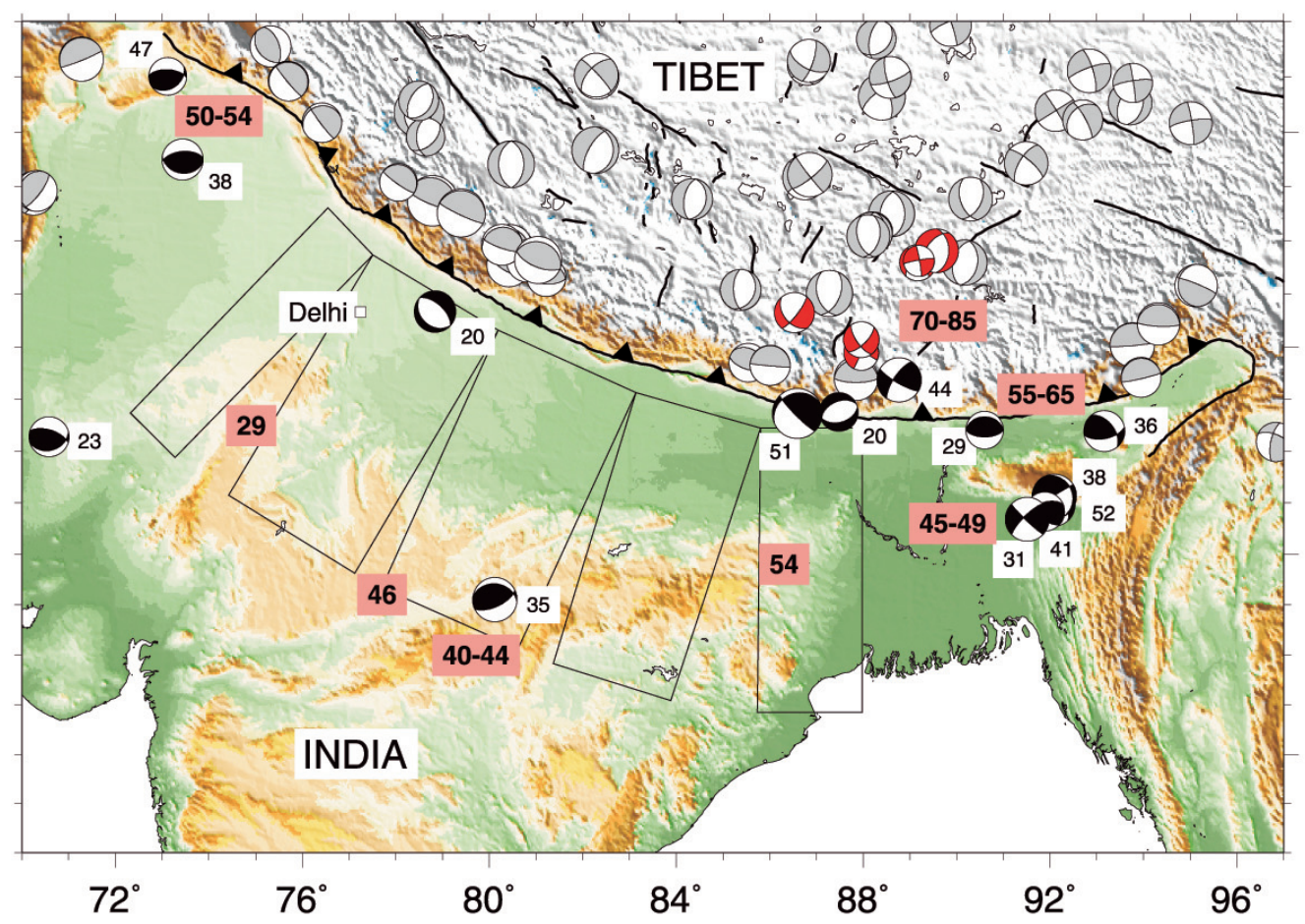

Figure 1. Earthquake focal mechanisms in India and southern Tibet. Focal spheres in black are those whose depth and location place them within the material of the Indian shield. Numbers next to those spheres are centroid depths (in km) determined by body wave modeling or direct observations of $\mathrm{pP}$ and sP phases. Red focal spheres are earthquakes at depths of 70-90 km beneath Tibet, discussed in the text. Light-gray spheres are shallow earthquakes in the Himalaya and Tibet, with centroid depths typically in the 10-15 km range. Boldface numbers in pink boxes are estimates of Moho depths in kilometers, from receiver functions (Yuan et al., 1997; Maggi et al., 2000a; Kumar et al., 2001), from refraction surveys (Murty et al., 1998), or from local seismic networks (Rai et al., 1999). Rectangular boxes in the foreland are those used for stacking the gravity profiles to produce Fig. 3B. 


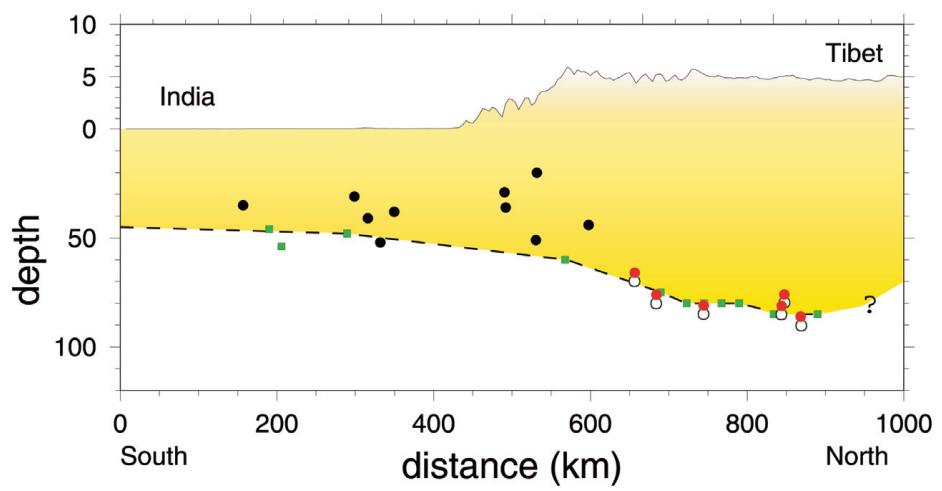

Figure 2. A cross section through Figure 1 along $90^{\circ} \mathrm{E}$ (note the different vertical exaggeration above and below sea level), with earthquakes and Moho depths projected onto the profile from up to $400 \mathrm{~km}$ on either side (in addition, the event at $35 \mathrm{~km}$ depth at $24^{\circ} \mathrm{N} 80^{\circ} \mathrm{E}$ has been included). Black and red symbols correspond to the same colored earthquakes in Figure 1. The red earthquakes have had their depths reduced by $4 \mathrm{~km}$ from their published depths (open circles) to allow for the overlying crustal velocities (see text). Green squares are Moho depth determinations, joined by a dotted line separating crust (yellow) from mantle.

\section{EARTHQUAKES AND GRAVITY}

It has been known for a long time that, in most places, earthquakes on the continents are confined to the upper half of the crust. But an important influence on the formulation of the jelly sandwich view was the occurrence of rare earthquakes in the uppermost mantle in a few areas, which were thought to indicate a strength contrast between the upper mantle and the generally aseismic lower crust (e.g., Chen and Molnar, 1983). Maggi et al. (2000a, 2000b) reexamined the evidence for these upper mantle earthquakes and concluded that they were instead in the lower crust. The pattern found by Maggi et al. is that earthquakes on the continents are restricted to a single layer (the seismogenic thickness, $T_{\mathrm{s}}$ ), usually the upper crust, but in some cases the whole crust, and that there is no convincing evidence for significant seismicity in the continental mantle. The main reason for this reevaluation was an improvement in the data quality since the study of Chen and Molnar (1983). More abundant seismic refraction and receiver function studies have led to better seismologically defined Moho depths, and more earthquakes, combined with improved body-waveform inversion programs, have led to clearer patterns of welldetermined centroid depths.

An important example is given in Figure 1, in an area once thought to be a type example of continental mantle seismicity. Black focal mechanisms are earthquakes in the foreland of the Himalaya and therefore within the underthrusting Indian shield. The depths of all these earthquakes have been determined by waveform modeling or by direct identification of the surface reflection phases $\mathrm{pP}$ and $\mathrm{sP}$, and all lie at or above the estimates of the Moho depth in their epicentral regions (Fig. 2). They are nearly all in the lower half of the Indian continental crust in this case. Most of these earthquakes are relatively small, with $\mathrm{M}_{\mathrm{w}} \sim 5.5$ and source dimensions of order $5 \mathrm{~km}$, so that even allowing for uncertainties in Moho and centroid depths, they are unequivocally in the lower crust.
For others, it might be argued that such uncertainties could just allow some of them to be in the uppermost mantle, but because we know the lower crust is seismically active, we suspect they are all above the Moho. An additional argument for a single seismogenic layer comes from the focal mechanisms themselves. The shallowest events (at $\sim 20 \mathrm{~km}$ ) show normal faulting, consistent with bending of the shield beneath the foreland basin. The deeper ones are mostly thrusts or strike-slip mechanisms with the $\mathrm{P}$ axis directed north, consistent with shortening in the lower part of the bending layer, as seen beneath the outer rises seaward of oceanic trenches (Chapple and Forsyth, 1979). If the deeper earthquakes were at the top of a separate strong upper mantle layer, they should show extension, not shortening. The single, thick seismogenic layer is partly responsible for the large fault areas and moments of the biggest earthquakes in the Indian shield, such as the 1897 earthquake beneath the Shillong plateau, whose fault plane ruptured between 9 and $45 \mathrm{~km}$ depth (Bilham and England, 2001), and the 2001 Bhuj earthquake in Gujarat (Withers, 2001).

The red focal mechanisms in Figure 1 are earthquakes in southern Tibet with confirmed depths between 70 and $90 \mathrm{~km}$, which are often cited as evidence of mantle seismicity (e.g., Chen and Molnar, 1983; Zhu and Helmberger, 1996). However, various new data have emerged about this area. First, it is now known from receiver functions in the very area of these earthquakes, that the Moho is between 70 and $85 \mathrm{~km}$, and deepest in the north (Yuan et al., 1997). Second, the depths of these events were estimated from pP-P and sP-P times assuming a crustal thickness of $60-70 \mathrm{~km}$, whereas if the crust were thicker, their depths would decrease by $\sim 4 \mathrm{~km}$. Third, Zhu and Helmberger (1996) concluded that the events were sub-Moho because various expected multiple S-wave reflections were apparently missing, cut out by the Moho discontinuity. However, we now know that the crust itself contains at least two sharp discontinuities that would have the same effect (Yuan et al., 1997), so this conclusion is not secure. Finally, these earthquakes are in a very special placeprecisely where an extrapolation of the Indian shield beneath Tibet would lead to near-Moho earthquakes if it were seismically active in the lowermost crust, as it is beneath the Himalayan foreland.

These data are summarized in the cross section in Figure 2. It takes little imagination to believe the earthquakes are all in the lower part of the Indian shield crust as it underthrusts Tibet to a latitude of $\sim 30^{\circ} \mathrm{N}$. Thus, this region is not a secure peg on which to hang a belief in mantle seismicity beneath the continents.

As well as examining the focal depth distribution on the continents, Maggi et al. (2000b) also reexamined the distribution of effective elastic thickness $\left(T_{\mathrm{e}}\right)$ estimates on the continents, building on the study of McKenzie and Fairhead (1997). $T_{\mathrm{e}}$ is the conceptual thickness of an elastic beam that supports gravity anomalies of up to a few hundred kilometers in wavelength produced by loading. Maggi et al. (2000b) concluded that $T_{\mathrm{e}}$ was everywhere slightly less than the seismogenic thickness $\left(T_{\mathrm{S}}\right)$ and that the two tracked each other. Thus, in places where earthquakes occurred down to 

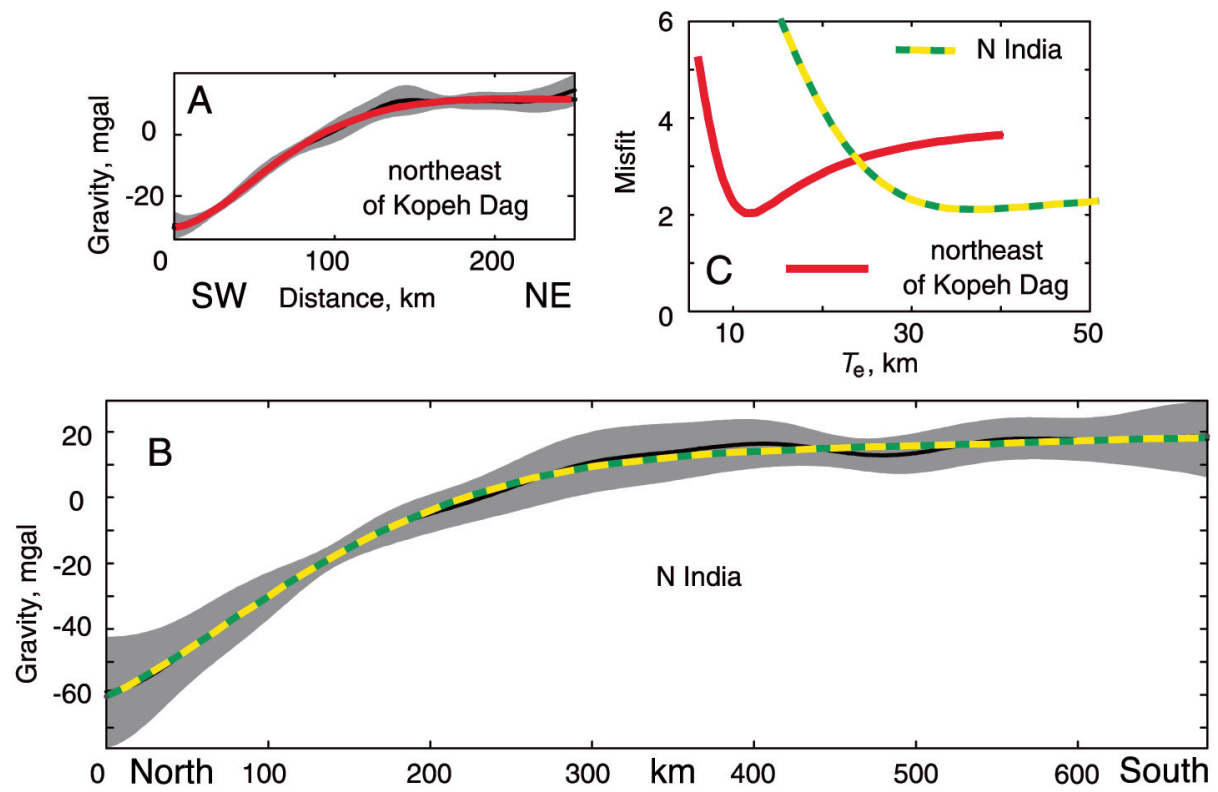

Figure 3. Stacked free-air gravity profiles across (A) the Kopeh Dag and (B) the Himalayan foreland basins, at the same scale. The solid black lines are the averages $\left(g_{\mathrm{m}}\right)$ of stacked profiles taken at $2 \mathrm{~km}$ spacing in the boxes shown in Figures 1 and 4 and the gray band shows the $\pm 1 \sigma$ range. The actual free-air gravity maps are shown in McKenzie and Fairhead (1997) and Maggi et al. (2000b). Colored lines are the modeled gravity profiles $\left(g_{c}\right)$ matched by bending an elastic plate of thickness $T_{\mathrm{e}}$. (C) The misfit:

$$
H^{2}=\frac{1}{N} \sum_{n=1}^{N}\left[\left(g_{\mathrm{m}}-g_{\mathrm{c}}\right) / \sigma\right]^{2}
$$

as a function of $T_{\mathrm{e}}$ for both regions. The greater wavelength of the Himalaya flexural signal is clear, requiring a $T_{\mathrm{e}}$ of $\sim 36 \mathrm{~km}$, compared with only $12 \mathrm{~km}$ for the Kopeh Dag (see also McKenzie and Fairhead 1997). the Moho (e.g., North India, northern Tien Shan) both $T_{\mathrm{e}}$ and $T_{\mathrm{S}}$ values were greater than in other places where earthquakes were confined to the upper crust alone. McKenzie and Fairhead (1997) and Maggi et al. (2000b) used two techniques to estimate $T_{\mathrm{e}}$, an analysis of the correlation between freeair gravity and topography in the frequency domain, and modeling of the flexural free-air gravity signal in foreland basins. The second technique is less controversial and is illustrated in Figure 3. It ignores topography altogether and makes only one important assumption, which is that the plate is bent only by loads and couples on its end.

Figure 3B shows a free-air gravity profile across the Himalayan foreland, in which the broad gravity low of the Ganges Basin is evident. The colored line shows the expected profile from the bending of an elastic plate of thickness $36.5 \mathrm{~km}$, the formal best-fitting value of $T_{\mathrm{e}}$. The value of the misfit between observed and calculated gravity profiles as a function of $T_{\mathrm{e}}$ has a quite broad and shallow minimum (Fig. 3C). The point is, however, that the $T_{\mathrm{e}}$ estimate for north India is clearly in the $30-50 \mathrm{~km}$ range, and quite different from the estimate obtained using the same technique for the foreland of the Kopeh Dag Mountains on the Iran-Turkmenistan border (Fig. 4), where earthquakes in the foreland are no deeper than $\sim 20 \mathrm{~km}$.
The $T_{\mathrm{e}}$ estimate for the Kopeh Dag foreland is $12 \mathrm{~km}$, with a much better defined minimum (Fig. 3C). The difference in $T_{\mathrm{e}}$ in the two forelands is directly reflected in the difference in width of the two gravity signals (Fig. $3 \mathrm{~A}$ and $3 \mathrm{~B}$ ), which are drawn at the same scale.

Other $T_{\mathrm{e}}$ estimates, and their comparison with $T_{\mathrm{s}}$ observations, are reported by Maggi et al. (2000b). They concluded that: (a) the continental lithosphere has only one seismogenic layer (typically the upper crust, but in some cases the whole crust); (b) there is no convincing evidence for significant seismicity in the continental mantle, and (c), $T_{\mathrm{e}}$ values are similar to, but a little less than, the thickness of the seismogenic layer.

\section{STRENGTH OF THE CONTINENTAL LITHOSPHERE}

The most obvious explanation for the observations summarized above is that the strength of the continental lithosphere resides in a single layer, which is the layer within which there are earthquakes. It would then be no surprise that the effective elastic thickness is somewhat smaller than the seismogenic thickness, for two reasons. First, the top few kilometers, especially in sediment-thick foreland basins, are unlikely to contribute much to the elastic strength. Second, $T_{\mathrm{e}}$ reflects the

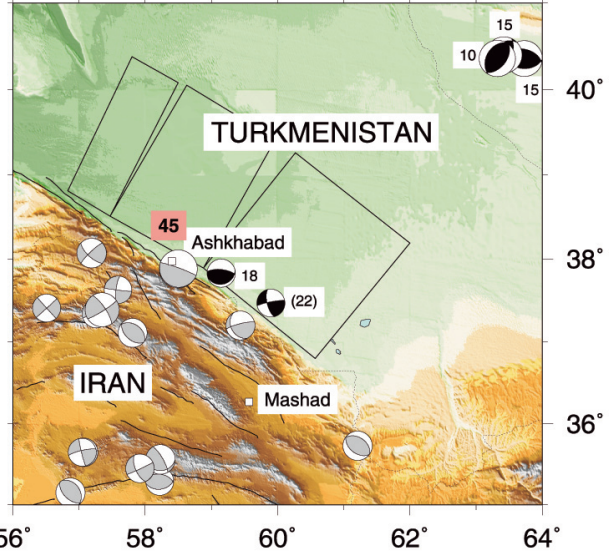

Figure 4. Earthquake focal mechanisms in the foreland region of the Kopeh Dag, with notation as in Figure 1. Earthquakes in the Turkmen shield have black focal spheres, with numbers indicating centroid depths in $\mathrm{km}$ determined by waveform modeling. The earthquake with its depth $(22 \mathrm{~km})$ in brackets was too small for long-period body wave modeling. Its depth of $22 \mathrm{~km}$ is from the relocated catalogue of Engdahl et al. (1998) and its depth determined by the Harvard Centroid Moment Tensor Project was 24 km. Light focal spheres are earthquakes in the thickened crust of the Kopeh Dag, with centroids all shallower than $15 \mathrm{~km}$ (Jackson et al., 2002). The Moho depth of $45 \mathrm{~km}$ near Ashkhabad is from a receiver function analysis by Mangino and Priestley (1998). Rectangular boxes in the foreland are those used for stacking the gravity profiles to produce Figure 3A. 
ability of the lithosphere to support loads over several million years, whereas the loading and unloading associated with the earthquake cycle happens on a much shorter time scale, over which the lithosphere might appear to be stronger. A corollary of this interpretation is that the continental mantle has no significant long-term strength.

However, all the analyses of gravity yield only an estimate of an elastic thickness, not the depth at which that elastic strength occurs. An alternative interpretation of the gravity could be that all or most of that strength lies in the mantle, rather than in the crust. It could also be argued that earthquakes are an indicator of frictional stability rather than strength, and that the continental mantle could still be strong despite being aseismic. The problem then is that, because $T_{\mathrm{e}}<T_{\mathrm{s}}$, it is also necessary to argue that the seismically active layer has long-term weakness, whereas the aseismic part has long-term strength. While this is possible in principle, it seems improbable and unnecessarily complicated. Nor are such complications needed in the oceans (see following section). The simpler explanation is that long-term strength resides in the seismogenic layer.

In the case of north India, it is also possible to say something about the creep strength of the mantle lithosphere. The Indian shield is bent under the Ganges Basin, and from the elastic thickness $(40 \mathrm{~km})$ and the amount of deflection $(\sim 10 \mathrm{~km}$ over $400 \mathrm{~km})$ we can estimate the strain necessary in the shortening mantle beneath the flexed lid to be about $2 \times 10^{-3}$. This happens over a time period of $\sim 10 \mathrm{Ma}$ needed to move the shield through the bending region, giving a strain rate of about $10^{-17} \mathrm{~s}^{-1}$. At this strain rate, the stresses in the mantle must be much less than those generated in the seismogenic elastic layer above. If that were not true, we would not see the change in focal mechanisms from shallow normal faulting to deeper thrusts within the crust. So at this strain rate, the creep strength of the mantle is much weaker than the elastic strength of the seismogenic layer.

The new view, in which the continental lithosphere contains a single strong layer, is similar to the longaccepted view of the oceanic lithosphere. Intraplate oceanic earthquakes occur to depths that correspond to $600-800{ }^{\circ} \mathrm{C}$, whereas oceanic elastic thicknesses correspond approximately to the shallower depth of the $450{ }^{\circ} \mathrm{C}$ isotherm, and thus $T_{\mathrm{e}}<T_{\mathrm{s}}$ (e.g., Wiens and Stein, 1983; Chen and Molnar, 1983; Watts et al., 1980). The main difference is that earthquakes and significant long-term strength certainly occur in the oceanic mantle, whereas they do not on the continents.

If this new view of the continents is correct, it is worth thinking why we were misled for so long. One reason was almost certainly the very success of the simple oceanic picture, in which elastic and seismogenic limits correspond to entirely reasonable values of homologous temperature (the ratio of actual temperature to melting temperature) in dry peridotite. It seemed reasonable to transfer this expectation of the mantle to the continents, using laboratory experiments on dry olivine as a proxy for dry mantle, in which case a strong uppermost mantle beneath the Moho would be expected (e.g., Brace and Kohlstedt, 1980; Chen and Molnar, 1983). It also seemed reasonable to interpret the few continental earthquakes near the Moho to be in the mantle rather than the crust, as Moho depths were generally poorly known, and a wet Si-rich lower crust was not expected to be seismically active. To be fair, the early papers that tried to relate laboratory creep and friction experiments to earthquake depths were aware of various other possibilities and urged caution (Brace and Kohlstedt, 1980; Chen and Molnar, 1983). But the extreme effect of temperature in activating creep mechanisms was well appreciated at the time, nothing else seemed necessary, and the simplicity of the laminated continental lithosphere model with the strong mantle was enthusiastically embraced by many of us.

Unease with that laminated model started to appear when some analyses of gravity and topography in the frequency domain began to yield $T_{\mathrm{e}}$ values of $100-130 \mathrm{~km}$ in some shield areas. If correct, these values required significant strength at depths corresponding to $\sim 1000{ }^{\circ} \mathrm{C}$ (McKenzie and Fairhead,
1997), far above the homologous temperatures at which such strength is expected, and far deeper than the deepest continental earthquakes. To argue that in a laminated system, the effective elastic thickness is only an abstract notion is no help here. A laminated system in which layer-parallel slip is permitted will always respond with an apparent elastic thickness that is smaller than its true thickness, requiring actual strength to a depth even greater than $T_{\mathrm{e}}$. McKenzie and Fairhead (1997) argued that the method used to obtain these large values of $T_{\mathrm{e}}$ yielded upper bounds only, and that the true $T_{\mathrm{e}}$ values were probably much smaller, being always less than $T_{\mathrm{s}}$.

If all the strength in the continental lithosphere resides in the crustal seismogenic layer, some other effect, in addition to temperature, must be important to distinguish continental and oceanic mantle and to allow the lower continental crust to be seismic in some areas and not in others. This is particularly clear in continental shields, where Moho temperatures can be as low as 300-500 ${ }^{\circ} \mathrm{C}$ (Artemieva and Mooney, 2001), so that the uppermost mantle is certainly cold enough to produce earthquakes, if that is the only relevant criterion (recall that earthquakes occur in the oceanic mantle to temperatures of at least $600{ }^{\circ} \mathrm{C}$ ). Maggi et al. (2000b) suggested that the additional important effect is provided by water, which is known to reduce creep strength dramatically, even if present as only a few parts per million in nominally anhydrous minerals (Hirth and Kohlstedt, 1996; Mackwell et al., 1998). They suggested that, in the oceanic mantle lithosphere, dry Si-poor rheologies are appropriate because any water that was present was lost during the melting beneath ridges. But the continental mantle may well have small amounts of water, either from a longterm percolation of metasomatic fluids or from episodes of subduction. Loss of water from the lower crust, to leave anhydrous granulite-facies assemblages, may also be responsible for the strength of the lower crust in some ancient shield areas, with the Moho acting as a permeability barrier to the long-term percolation of fluids from below. The 

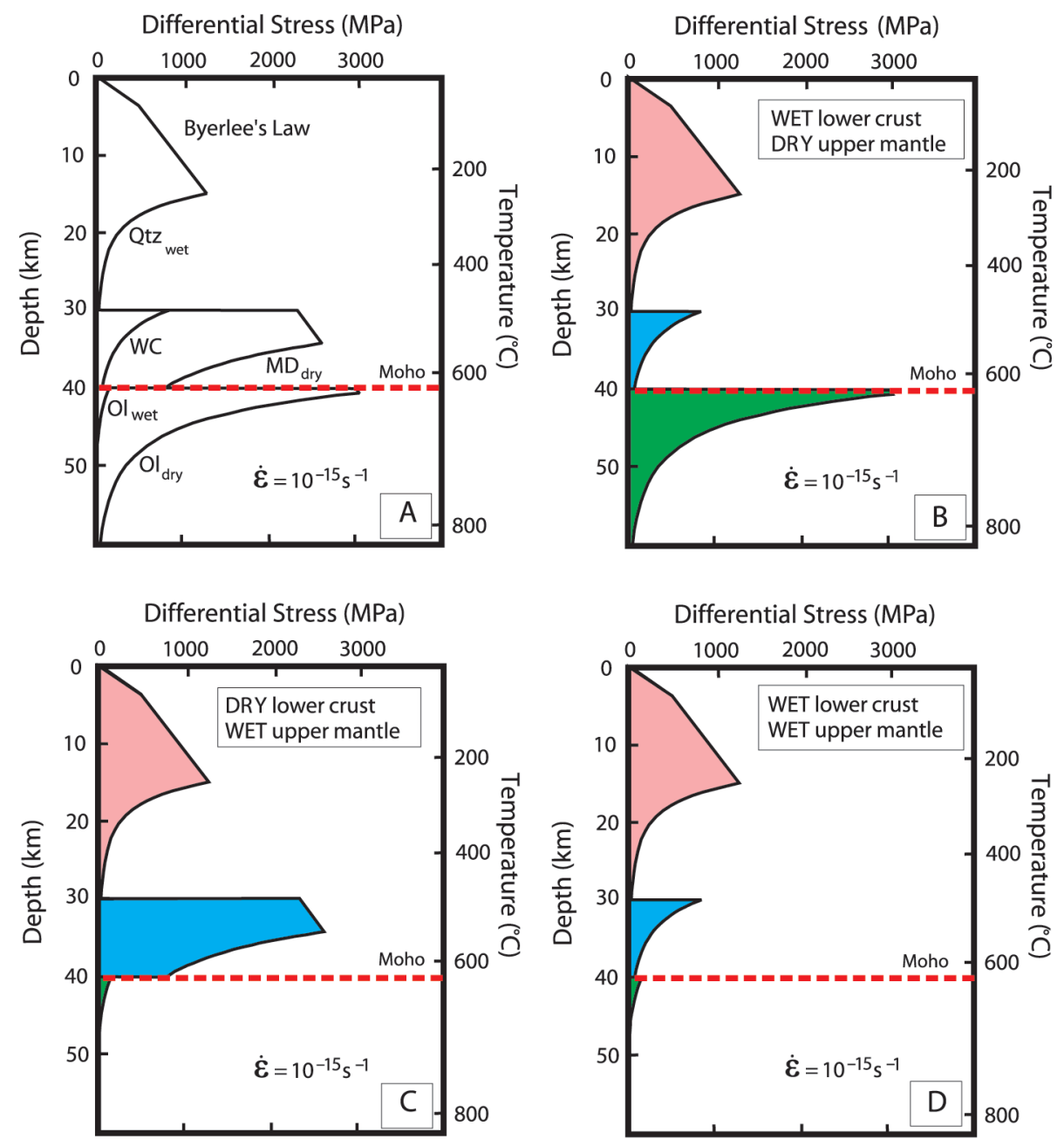

Figure 5. Strength envelopes of differential stress (essentially rock strength) versus depth for various continental conditions, to illustrate the potential effects of water (adapted from Mackwell et al., 1998). The Moho is at $40 \mathrm{~km}$ and the temperature variation with depth corresponds to a surface heat flow of $60 \mathrm{mWm}^{-2}$. In all cases, the upper crust is represented by wet quartz (Qtz) and frictional strength by Byerlee's law. A. A summary of experimental results, in which the lower crust is represented by dry diabase (MD) or undried granulite (WC), and the mantle by dry or wet olivine (OI). B. Wet lower crust and dry upper mantle, showing the popular conception of the continental lithosphere for the past 20 years, involving a weak lower crust and strong upper mantle. C. Dry lower crust and wet upper mantle, showing a strong lower crust over a mantle that has no strength, which may represent conditions under some continental shields, such as north India. D. Wet lower crust and wet upper mantle, neither of which have significant strength. In this case, nearly all strength resides in the seismogenic upper crust, which may represent conditions in most continental areas.

detailed suggestions of Maggi et al. (2000b) depend on petrological and melting inferences that have not yet been tested. In this respect, the observations of Austrheim and Boundy (1994) and Austrheim et al. (1997) from the Norwegian Caledonides are particularly interesting. They describe psuedotachylites (friction-generated melts) that formed under eclogite conditions at depths of $60 \mathrm{~km}$ or more, with the transformation to eclogite facies assemblages occurring during shear failure in metastable dry granulites only when hydrous fluids are present. These circumstances may well be relevant to the deep earthquakes beneath southern Tibet.

It is clear that water has the potential to influence lithosphere strength dramatically. Figure 5 shows a series of theoretical profiles based on laboratory experiments, contrasting the expected behaviors of representative dry and wet lower crust and mantle combinations (adapted from Mackwell et al., 1998). This figure is included not because such profiles should be taken literally, but to illustrate the effect of small amounts of water on creep strength.

\section{IMPLICATIONS}

If significant strength resides only in the seismogenic layer of the continental lithosphere, it would not be surprising if regional patterns of active faulting at the surface were dominated by the strength of the crustal blocks and the interactions between them. The strength of the faults themselves is then presumably a limiting factor in crustal behavior, but remains very uncertain (e.g., Scholz, 2000). Maggi et al. (2000b) suggested that the heights of mountains and plateaus correlate with the strength of their bounding forelands, with higher mountains requiring greater support. The large buoyancy force needed to support Tibet is equivalent to average deviatoric stresses of $\sim 120 \mathrm{MPa}$ if contained within the $40-\mathrm{km}$-thick elastic layer of India, greatly exceeding the average stress drops observed in earthquakes of 1-10 MPa. But the faults in the Himalayan foreland are not required to sustain $100 \mathrm{MPa}$ stresses if most of the seismogenic layer in the Indian shield is intact. In places where the seismogenic layer is pervasively ruptured by faulting, such as in regions of distributed extension on parallel normal faults, topographic contrasts and the stresses required to maintain them are much less, and approach the levels of the stress drops seen in earthquakes (e.g., Jackson and White, 1989).

In the studies summarized here, it is perhaps the contrast between the shields and the deforming regions that is most dramatic. The earthquakes in Figures 1 and 2 suggest the Indian shield underthrusts Tibet at least as far as $30^{\circ} \mathrm{N}$. Huang et al. (2000) traced the lack of shear wave anisotropy that is characteristic of the Indian shield even farther, to $32^{\circ} \mathrm{N}$, and the gravity in Figure $3 \mathrm{~B}$ suggests that the shield is strong. If these interpretations are correct, the strong Indian shield underlies most of the region of active normal faulting in southern Tibet (see Fig. 1), making it 
improbable that there is a link between the surface extension and any convective downwelling in the mantle, as is often envisaged. Instead, it is perhaps more likely that the high elevations in this region are supported by the flexure of the Indian shield, with the entire overlying region 300-400 km north of the Himalayan front falling towards India, causing arc-normal slip vectors on the thrusts and arc-parallel extension behind.

If, at least in some places, the lower crust is stronger than the upper mantle, it is also necessary to reexamine the conditions under which the lower crust can flow to even out crustal thickness contrasts, as it has done in some areas, particularly in extensional metamorphic core complexes (e.g., Kruse et al., 1991; McKenzie et al., 2000). On the scale of 100-200 km, most of the interesting characteristics of lower crustal flow, such as the extreme dependence of relaxation time on wavelength and the generation of topographic fronts, occur because there are strong vertical shear gradients within the flowing channel. Such gradients require a viscosity contrast in which the mantle is more viscous than the lower crust, not less. It is probable that special circumstances are needed to reduce the viscosity of the lower crust to make it flow on this scale, such as the intrusion of igneous melts or the addition of water-rich fluids. In both cases, the important features of the flow arise from the limited time over which the viscosity is reduced, controlled either by conductive cooling of intrusions or by the separation of melt from its matrix, which removes water (McKenzie and Jackson, 2002). Lower-crustal flow on much larger scales, such as that envisaged over $>1000 \mathrm{~km}$ around parts of Tibet (Clark and Royden, 2000), is only likely to happen in reasonable time scales if the viscosities of both the lower crust and the mantle are low, when flow can occur quickly by pure shear.

\section{CONCLUSIONS}

The view of the continental lithosphere presented here, in which strength resides only in a single seismogenic layer, is easy to reconcile with the new earthquake and gravity interpretations, and is likely to involve processes in rock mechanics and petrology that are understood in principle, even if they remain to be tested in detail. By contrast, the jelly sandwich model, which includes significant strength in the continental mantle, requires an obscure relationship between $T_{\mathrm{s}}$ and $T_{\mathrm{e}}$ and, if the large values of $T_{\mathrm{e}}$ are still believed, substantial long-term strength at temperatures where rocks are expected to be very weak. At the moment, our views of continental tectonics are confused by not knowing what really controls the patterns of deformation we see at the surface. At length scales much larger than the lithosphere thickness, it is probable that deforming velocity fields are related to forces on the edges of the lithosphere that arise from plate motions or within the lithosphere that arise from crustal thickness contrasts (e.g., England and Molnar, 1997; Flesch et al., 2000). If the new views proposed here are correct, the detailed patterns of faulting on the scales of interest to most tectonic and structural geologists (say, 100-400 $\mathrm{km}$ ) are likely to be controlled predominantly by the strength of the crustal blocks and the faults that bound them.

\section{ACKNOWLEDGMENTS}

It is a pleasure to acknowledge that I have been greatly influenced by discussions with my colleagues Dan McKenzie and Keith Priestley, as well as with Philip England, Peter Molnar, and David Kohlstedt, though they may not agree with all the interpretations expressed here, and I alone am responsible for any errors or misconceptions. I thank Dan McKenzie for help in producing Figure 3. Cambridge Earth Sciences contribution ES 7077.

\section{REFERENCES CITED}

Artemieva, I.M., and Mooney, W.D., 2001, Thermal thickness and evolution of Precambrian lithosphere: A global study: Journal of Geophysical Research, v. 106, p. 16,387-16,414

Austrheim, H., and Boundy, T.M., 1994, Psuedotachylites generated during seismic faulting and eclogitization of the deep crust: Science, v. 265, p. 82-83.

Austrheim, H., Erambert, M., and Engvik, A.K., 1997, Processing of crust in the root of the Caledonian continental collision zone: The role of eclogitization: Tectonophysics, v. 273 , p. $129-153$.

Bilham, R., and England, P., 2001, Plateau "pop-up" in the great 1897 Assam earthquake: Nature, v. 410, p. 806-808.

Brace, W.F., and Kohlstedt, D.L., 1980, Limits on lithostatic stress imposed by laboratory experiments: Journal of Geophysical Research, v. 85, p. 6248-6252.

Chapple, W.M., and Forsyth, D.W., 1979, Earthquakes and the bending of plates at trenches: Journal of Geophysical Research, v. 84, p. 6729-6749.
Chen, W-P., and Molnar, P., 1983, Focal depths of intracontinental and intraplate earthquakes and their implications for the thermal and mechanical properties of the lithosphere: Journal of Geophysical Research, v. 88, p. 4183-4214.

Clark, M.K., and Royden, L.H., 2000, Topographic ooze: building the eastern margin of Tibet by lower crustal flow: Geology, v. 28, p. 703-706.

Engdahl, E.R., van der Hilst, R., and Buland, R., 1998, Global teleseismic earthquake relocation with improved travel times and procedures for depth determination: Bulletin of the Seismological Society of America, v. 88, p. 722-743.

England, P., and Molnar, P., 1997, Active deformation of Asia: From kinematics to dynamics: Science, v. 278, p. 647-650.

Flesch, L.M., Holt, W.E., Haines, A.J., and Shen-Tu, B. 2000, Dynamics of the Pacific-North American plate boundary in the western United States: Science, v. 287 p. 834-836.

Hirth, G., and Kohlstedt, D.L., 1996, Water in the oceanic upper mantle: Implications for rheology, melt extraction and the evolution of the lithosphere: Earth and Planetary Science Letters, v. 144, p. 93-108.

Huang, W.C., Ni, J.F., Tilman, F., Nelson, D., Guo, J., Zhao, W., Mechie, J., Kind, R., Saul, J., Rapine, R., and Hearn, T. 2000, Seismic polarization anisotropy beneath the central Tibetan Plateau: Journal of Geophysical Research, v. 105, p. $27,979-27,989$.

Jackson, J.A., and White, N.J., 1989, Normal faulting in the upper continental crust: Observations from regions of active extension: Journal of Structural Geology, v. 11, p. 15-36.

Jackson J., Priestley, K., Allen, M., and Berberian, M., 2002, Active tectonics of the South Caspian Basin: Geophysical Journal International, v. 148, p. 214-245.

Kruse, S., McNutt, M., Phipps-Morgan, J., Royden, L., and Wernicke, B., 1991, Lithospheric extension near Lake Mead, Nevada: A model for ductile flow in the lower crust: Journal of Geophysical Research, v. 96, p. 4435-4456.

Kumar, M.R., Saul, J., Sarkar, D., Kind, R., and Shukla, A.K., 2001, Crustal structure of the Indian shield: New constraints from teleseismic receiver functions: Geophysical Research Letters, v. 28, p. 1339-1342.

Mackwell, S.J., Zimmerman, M.E., and Kohlstedt, D.L., 1998, High-temperature deformation of dry diabase with application to tectonics on Venus: Journal of Geophysical Research, v. 103, p. 975-984.

Maggi, A., Jackson, J.A., Priestley, K., and Baker, C., 2000a A reassessment of focal depth distributions in southern Iran the Tien Shan and northern India: Do earthquakes really occur in the continental mantle?: Geophysical Journal International, v. 143, p. 629-661.

Maggi, A., Jackson, J.A., McKenzie, D., and Priestley, K. 2000b, Earthquake focal depths, effective elastic thickness, and the strength of the continental lithosphere: Geology, v. 28 , p. $495-498$.

Mangino, S., and Priestley, K., 1998, The crustal structure of the southern Caspian region: Geophysical Journal International, v. 133, p. 630-648.

McKenzie, D., and Fairhead, D., 1997, Estimates of the effective elastic thickness of the continental lithosphere from Bouguer and free air gravity anomalies: Journal of Geophysical Research, v. 102, p. 27,523-27,552.

McKenzie, D., and Jackson, J.A., 2002, Conditions for flow in the crust: Tectonics (in press).

McKenzie, D., Nimmo, F., Jackson, J., Gans, P., and Miller, E., 2000, Characteristics and consequences of flow in the crust: Journal of Geophysical Research, v. 105, p. $11,029-11,046$

Molnar, P., 1992, Brace-Goetze strength profiles, the partitioning of strike-slip and thrust faulting at zones of oblique convergence, and the stress-heat flow paradox of the San Andreas fault, in Evans, B., and Wong, T-F., eds., Fault mechanics and transport properties of rocks: San Diego, California, Academic Press, p. 461-473.

Murty, A.S.N., Mall, D.M., Murty, P.R.K., and Reddy, P.R., 1998, Two-dimensional crustal velocity structure along Hirapur-Mandla profile from seismic refraction and wide-angle reflection data: Pure and Applied Geophysics, v. 152 , p. $247-266$ 